\title{
O Sujeito na Cidade: psicanálise, laço social e invenção
}

Sébastien Ponnou'

\author{
'Université de Rouen-Normandie, Rouen - França
}

RESUMO - O Sujeito na Cidade: psicanálise, laço social e invenção. A clínica psicanalítica testemunha cotidianamente os tesouros simbólicos e imaginários que os adolescentes extraem na cidade, a fim de enfrentar às situações psíquicas e sociais complexas. Se consideramos o laço social como um fato de linguagem ou modalidade singular de inscrição do sujeito na linguagem, então, a psicanálise se torna um recurso inesgotável para acompanhamento e apoio de adolescentes vulneráveis. Discutiremos essa proposição tomando como referência os ensinos de Sigmund Freud, Jacques Lacan, Jacques-Alain Miller e apoiando-nos em uma apresentação clínica extraída de nossa prática com adolescentes.

Palavras-chave: Clínica. Psicanálise. Lacan. Violência sexual. Sintoma.

ABSTRACT - The Subject in the City: psychoanalysis, social bond and invention. The clinic testifies daily the symbolic and imaginary treasures that adolescents draw on the city in order to face the complex psychic and social situations. If we consider the social bond as a fact of language, or a particular way of inscribing the subject in language, then psychoanalysis becomes an inexhaustible resource in the accompaniment and support of these vulnerable adolescents. We will discuss this proposal with reference to the teachings of Sigmund Freud, Jacques Lacan, and Jacques-Alain Miller - and with the support of a clinical presentation taken from our practice with adolescents.

Keywords: Clinic. Psychoanalysis. Lacan. Symptom. Adolescence.

Educação \& Realidade, Porto Alegre, v. 46, n. 1, e109165, 2021. 


\section{Introdução}

A psicanálise não deve ser entendida apenas como o que opera por trás das portas fechadas do tratamento analítico. Os conceitos e a prática analítica há muito tempo ultrapassaram o seu enquadre para referenciar o trabalho voltado ao cuidado ou à educação em instituições na cidade.

Se consideramos o laço social como um fato de linguagem ou modalidade singular de inscrição do sujeito na linguagem, então, a psicanálise torna-se um refúgio e um recurso inesgotável para acompanhamento e apoio de pessoas mais vulneráveis. Reciprocamente, a psicanálise sempre ocupou um lugar importante no campo social, uma vez que ela é a única abordagem a responder aos fenômenos de transferência, de resistência ou do sintoma, os quais são o signo de outra cena: o inconsciente e o gozo - origem do inelutável mal-estar na civilização.

À medida que a psicanálise interpreta o sintoma social no particular de cada um, ela restitui ao sujeito sua responsabilidade e sua possibilidade criativa em relação ao Outro e ao laço social. Abrem-se as modalidades renovadas de inscrição do sujeito na cidade, na qual a dimensão de invenção prima sobre as normas, os determinismos e as soluções pré-estabelecidas. Partindo desses remanejamentos em curso no tecido contemporâneo do laço social, iremos declinar de diferentes questões para referirmo-nos aos ensinos de Sigmund Freud, Jacques Lacan e Jacques-Alain Miller - apoiando-nos em uma apresentação clínica extraída de nossa prática com adolescentes em instituição especializada.

\section{O tecido contemporâneo do laço social}

O século XXI se caracteriza por profundos remanejamentos no tecido do laço social, marcados pela pregnância do capitalismo e da ciência na trama contemporânea dos discursos (Lacan, 1991; Lacan, 2011; Lacan, 1972; Bruno, 2010; Sauret, 2009; Sauret, 2012). Esses agenciamentos simbólicos promovem novas modalidades de relação do sujeito com o real (Miller et al., 2012; Miller et al., 2013) e, por conseguinte, impactam no conjunto de práticas e dispositivos institucionais do trabalho desenvolvido no campo social.

Nossa atualidade consagra o declínio das ontologias, das instituições e das figuras de autoridade a uma pretensão universal. As balizas tradicionais do laço social não servem mais como receita, pois são suplantadas pelo capitalismo e pela ciência, sobre os quais Lacan (1972) ironizou respectivamente como foraclusão da castração, do impossível, e foraclusão do sujeito (Lacan, 2001)... Passagem da heteronomia à autonomia, que interroga as modalidades contemporâneas do laço social sem Outro para o garantir.

Enquanto o mistério e a incompletude regem o coletivo e o particular das sociedades tradicionais, a plenitude moderna é paga por meio da inconsistência e da virtualização do laço social. Essa liberação ge- 
neralizada é desmascarada e imediatamente aparece sua face obscena, segura e reacionária. O sujeito moderno dispensa o Outro, e a lei desse Outro, e satisfaz-se com o narcisismo e o jogo do Um. Isso que constitui o laço social não é mais o pai, mas, como dizia Jacques-Alain Miller, é a comunidade dos irmãos do gozo provocando um certo extravio, uma certa multiplicidade de modos de gozo e de pulsão de morte.

O laço social não é mais garantido pelo mestre, vetor de alteridade, mas pelo mercado, contanto que mais facilmente o sujeito esteja disposto a sacrificar sua preservação em nome de seu gozo. A saída mais garantida depende, então, de uma política do sintoma que visa promover a singularidade do gozo do sujeito para fazer um furo ou desempenhar o papel terceiro no Um dos gozos do mundo.

Essa perspectiva desvela a mutação da relação do sujeito moderno ao seu próprio gozo. A função revolucionária seguramente insurrecional do sintoma consiste em dissolver a figura do proletário como sintoma do capitalismo para realizar a base da ação política quando ela é esclarecida pelo prisma analítico: não interpretar o sintoma social, senão na particularidade de cada um. Certamente, os remanejamentos simbólicos que operam no tecido contemporâneo do laço social induzem uma pluralização de modos de gozos, assim como uma dispersão de identificações e de modos de defesa do sujeito face ao real. Não obstante, a clínica - notadamente, a clínica com adolescentes - testemunha cotidianamente os tesouros simbólicos e imaginários que o sujeito fisga na cidade, a fim de estruturar as aparelhagens significantes e as suplências, permitindo-lhe fazer face às situações psíquicas e sociais complexas. A respeito disso, o caso de Suzon pode ser considerado paradigmático, porquanto ele testemunha os vieses pelos quais um acontecimento traumático - a ocorrência de uma violência sexual - pode fragilizar a articulação mais íntima da sexuação e do ser do sujeito. O relato propõe uma série de afloramentos clínicos para ilustrar as modalidades segundo as quais o discurso analítico contribui para defender a invenção de uma solução elegante e permite ao sujeito percorrer a cidade para introduzir a sua possibilidade criativa e se inscrever de maneira original em algum modelo de laço social.

\section{Ser um menino}

Suzon tinha dezesseis anos quando realizou a sua primeira sessão. Suas roupas estavam sujas e estragadas. Ela escondia o olhar atrás de uma longa franja. Seu rosto estava furado pelos piercings, alguns furos foram realizados por ela, selvagemente, enquanto estava hospitalizada.

A adolescente se refugiou em meu consultório: ela se recusava a encontrar as meninas da casa: o olhar do Outro a perseguia. Mais que isso, Suzon não compreendia porque deveria integrar-se na casa com as meninas, visto que ela queria ser acolhida somente na internet dos meninos... Surpreendido, eu a interroguei: "Na internet dos meninos"? 
"Sim, é meu projeto", ela respondeu com um largo sorriso e de forma irônica; "eu quero me tornar um menino".

Suzon entra em conversação a partir dessa fórmula um pouco enigmática, evocando o look andrógino - sua roupa, seu corte de cabelo, seu estilo emo. Essa referência aos emos reveste-se de um valor particular para Suzon, tem um significado pleno, para além das múltiplas identificações imaginárias nas quais ela se apoiava, uma nominação eletiva, uma suplência que lhe permitia alojar a sua singularidade no Outro e no laço social depois da ruptura das referências simbólicas e imaginárias que lhe abrigavam.

\section{Abuso sexual}

O acolhimento de Suzon em uma instituição especializada foi decidido depois de uma longa hospitalização em um serviço psiquiátrico para adolescentes, à qual ela foi submetida após uma agressão qualificada como abuso sexual cometida por um jovem adulto com quem Suzon se relacionava: “Eu não soube como dizer não", ela explica enquanto encolhe os seus ombros.

O abuso sexual produz o efeito de uma bomba (Dupont, 2020): não somente deflagrou como atingiu as identificações primordiais, conforme Suzon revelava como "a insondável decisão da sexuação"; mas tocou igualmente os fundamentos da célula familiar, enviando os pais da jovem de volta a uma forma insuportável que limita à rejeição - a foraclusão: "Nós entendemos que Suzon não fará nada em sua vida, que ela terminará na rua como uma desgovernada". Presa ao fantasma parental, a violência sexual faz o papel de ponto de condensação de um gozo intratável, do qual Suzon traz irremediavelmente a marca, ao ponto de encarnar no real essa palavra profética.

Na realidade, as dificuldades de Suzon não surgiram no momento do trauma inaugural, mas na sua retomada a posteriori pelo desvio do discurso parental e social, estabelecendo uma entrada insidiosa no sofrimento marcada por uma querela de sintomas: evasão escolar progressiva, exclusão do liceu, estado depressivo e degradação manifesta do estado físico da adolescente - divagação e mutilações - que a conduziram a uma hospitalização e a uma notificação. A qualificação de abuso sexual será rejeitada. Em contrapartida, uma medida socioeducativa em meio aberto será ordenada pelo judiciário em complemento ao cuidado.

Assim, o caso de Suzon ressalta a ideia de que a dimensão da violência sexual não está reduzida ao real do ato ou do acontecimento e convida-nos a abordar a dimensão do trauma em um tripé de temporalidade:

1) primeiro, a própria violência sexual, o real do ato - o abuso sexual submetido a Suzon;

2) em seguida, a retomada do acontecimento traumático no discurso do Outro, que opera uma transmissão do real aos registros simbó- 
licos e imaginários, ou seja, a fixação do trauma a um universo de sentido ou a um saber. Se o aparato simbólico do acontecimento reduz seu significado traumático através da palavra como morte da coisa (Freud, 2002, p. 5-6; Lacan, 1966, p. 319), o gozo encapsulado no significante contamina o campo da linguagem e torna-se falante (Miller, 1998-1999; Miller, 2011). A própria palavra pode, então, assumir um significado traumático;

3) enfim, a conversão do trauma em sintoma: a metabolização simbólica do trauma se torna sensível ao trabalho do inconsciente e aos esforços de composição do sujeito para tratar o gozo - no caso de Suzon, há os sintomas do corpo (os piercings selvagens que ressoam como a iteração do acontecimento traumático sobre o corpo) e também os sintomas sociais (problemas de escolarização, marginalização social...) - abrindo um deslocamento do impossível a sustentar as soluções susceptíveis de fazer borda ao inominável (Lacan, 1977; Freud, 2002; La Sagna, 2014).

\section{A questão da sexução ou a invenção de uma solução elegante}

Diante da violência sexual a que fora submetida e do olhar que revela uma desagregação radical do sujeito quanto ao campo do Outro, a referência aos emos e a mudança de identidade de gênero aparecem como soluções possíveis que permitem a Suzon fazer borda ao gozo. Além dos traços identificatórios concernentes a cada uma daquelas referências (maquiagem e vestimentas, piercings, corte de cabelo "estilo garoto"), o significante "emos" funcionava como uma nominação: é um sintoma que permite solucionar, pelo recurso imaginário, as lacunas abertas no real pela violência sexual e no simbólico, colocando em abismo o Outro.

Sem dúvidas, é um achado, uma vez que o significante emos é, no início, retirado do Outro. O caráter de invenção e o uso particularizado desse significante são manifestos se reportarmo-nos à questão da sexuação e do sexual - Éros. Ao lado da clássica divisão de gênero menino/menina e da escolha do objeto hetero/homo, Suzon cria uma terceira saída: o emo! Ela empurra o registro de invenção até a questão da sexuação, isto é, vai além da divisão tradicional: hetero/homo/emo. A adolescente faz uma provocação, com ironia, em direção ao Outro e testemunha sua capacidade de instrumentalizar a linguagem para fazer algo com o seu traumatismo (Miller, 2004a).

\section{Errância e clínica das bordas}

As soluções construídas por Suzon irão, ainda assim, confrontá-la a um certo número de dificuldades: o laço com os seus pais - por menos complexo e ambivalente que seja - encontrar-se-á ainda impedido... No colégio, o diretor exigirá uma escolha entre a escola e os piercings e 
preferirá pronunciar uma exclusão em vez de defender um acolhimento particularizado. Dentro da instituição, o trabalho de cuidado é colocado em risco pela fugas cotidianas e sistemáticas à tarde, porquanto Suzon saía para juntar-se aos seus amigos emos.

Enquanto a instituição torna rígida suas posições sob o risco de inscrever-se na série dos Outros cruéis (Miller, 2010), eu me engajo na política do sintoma (Soler, 1998), suscetível de defender um trabalho de composição de Suzon. De fato, a dimensão da invenção implica que "ao menos outro" pudesse colocar em ato. Nessa perspectiva, eu me esforço para fazer-me parceiro das invenções de Suzon, implantando uma clínica das bordas (Stevens, 2018), ciente de que o quadro não faz a obra e de que a instituição é uma cena cuja função é colocar o sujeito no pódio.

Assim, eu autorizo Suzon a utilizar o telefone do consultório para entrar em contato com seus amigos emos. Juntos, nós cartografamos suas errâncias em diferentes lugares da cidade. Em dois momentos, Suzon telefonará para mim, a fim de solicitar que um educador vá à sua procura.

Um jogo de idas e vindas se engaja, então, entre os diferentes lugares: da instituição e de um lugar da cidade onde Suzon reencontra seus amigos emos. Á repetição de situações de abuso - quantias recorrentes em dinheiro às quais ela consente, depois de solicitações sexuais que ela recusa (dessa vez, Suzon disse "não”!) - conduziram a adolescente a interrogar os sentidos de sua presença nesses lugares, pelos pequenos toques, até ela ficar ausente: "Lá é para pessoas que perderam sua vida. Eu não quero perder a minha”.

\section{Virar a cabeça dos rapazes}

Suzon cessará progressivamente suas fugas, na proporção em que deixará de ser uma referência para os emos. As novas demandas começarão a aparecer: escolarizada em um ambiente especializado, Suzon desejará retornar aos seus estudos, quer fazer estágios e trabalhar "como os jovens de sua idade". Isso que se revelava, até então, como iteração, a nomeação eletiva depois da ampliação significante, articulase, de agora em diante, em cenários, como novas modalidades de nós ainda frouxos, mal ajustados, aos quais a adolescente tenta ajustar com entusiasmo. Suzon busca ampliar bastante suas margens, ela quer estar atualizada! A parte imaginária e a função sintomática de sua demanda "ser do liceu - lycéenne", "ser estudante", "ser estilista", "ser cabeleireira" - ou seja, fazer um nome a partir dos significantes que ela toma por empréstimo do Outro - conduzindo a equipe a privilegiar uma escolaridade equipada em um liceu privado, liberado de imperativos acadêmicos ordinários, propondo cursos pela manhã e a possibilidade de estágios profissionalizantes pela tarde.

Suzon começa a ter mais cuidado consigo, com o seu corpo, com os estilos das vestimentas. Ela deixa os seus cabelos crescerem e tingeos regularmente, retira os seus piercings, um a um, e permite regenerar 
os orifícios que ela tinha forçado em seu corpo - especialmente em seu rosto. Ela estabelece relações mais apaziguadas com os seus pais que, a partir de agora, passam os finais de semana com ela.

Durante a sua passagem pelo liceu, ela passa a ter novos encontros e retorna à instituição "com histórias sobre garotas e garotos". A questão da identidade de gênero continua impregnada, e Suzon encontra um novo modo de resolução: ela quer agora ser "a menina que faz virar a cabeça dos homens”. Suzon começa a entrar em sedução. Ela veste-se muito feminina, procura capturar o olhar do outro, posicionase como objeto do desejo e encontra um prazer jubilatório ao furtar-se aos avanços que lhe são dirigidos: ela brinca com o Outro e subtrai-se diante das investidas desse Outro. Ela maneja a dimensão de engodo, da mascarada e de semblante...

A violência sexual atingiu Suzon ao ponto de fazer vacilar sua identidade de gênero. É por meio dos semblantes (tanto os emos como os jogos de sedução) - seja pelo viés disso que é um substituto para a relação sexual como fundamentalmente impossível - que ela chegará a reencontrar-se nos emaranhados da sexuação.

No momento de atingir a sua maioridade, Suzon se prepara para ingressar em um serviço como camareira. Além disso, engaja-se em uma formação e em estágios de venda.

\section{Psicose, clínica irônica, laço social e metamorfose}

Segundo várias perspectivas, Suzon se apresenta com traços da psicose ordinária (Miller, 1999a): não há sintoma neurótico aparente, não há delírio nem alucinação, mas uma forma de inibição e uma aspiração depressiva que justificaram uma hospitalização de longa duração e os cuidados em seguida. Se vários argumentos justificam uma melancolia ou uma esquizofrenia, o registro sobre o sintagma da psicose ordinária justifica-se na medida em que:

1) Suzon testemunha a permanência do aprofundamento de uma violação fundamental articulada ao mais íntimo do sentimento da vida (Lacan, 1966, p. 558);

2) há a pregnância de alguns fenômenos de corpo: cortes, piercings selvagens, andar vagando;

3) uma forma de errância toca os seus trajetos pela cidade ao modo da indeterminação do seu desejo;

4) ela testemunha igualmente uma regulação quase sistemática sobre as identificações imaginárias lábeis, como consequência de um encurralamento sobre o eixo a - a' (Lacan, 1966, p. 571), uma forma indeterminada e de precariedade identificatória decalcada sobre os traços do parceiro e pela via de consequência, um impedimento à dialética desejante. Essa modalidade de estrutura traz dois efeitos maiores: ela torna Suzon particularmente vulnerável às veleidades do gozo do Ou- 
tro: conformidade, sugestionabilidade, tendência a posicionar-se como objeto do gozo do Outro - repetição das situações de abuso. De um lado, essa labilidade identificatória abre para Suzon a possibilidade de inventar a série de soluções, permitindo-lhe tratar a espinhosa questão do gozo, o enigma do desejo do Outro e do traumatismo da violência sexual;

5) sobretudo, o sintagma da psicose ordinária tem o valor particular de sua inscrição em uma clínica irônica (Miller, 1993), ressaltando as capacidades de invenção e de composição do sujeito em sua relação com o Outro e com o laço social (Beraud, 2018).

Se, na abordagem da psicanálise, o laço social é considerado um fato de linguagem, a experiência clínica evidencia um paradoxo concernente à psicose. Ela mostra que o sujeito psicótico encontra um lugar, de um modo ou de outro, na sociedade e que, portanto, para ele, o laço social está desfeito. O modo de ser que caracteriza a posição do sujeito psicótico em relação à estrutura da linguagem consiste em estar, às vezes, dentro da cidade e fora do laço social (Naveau, 2004). A psicose coloca a questão do laço social sob a forma de paradoxo, ao qual ela responde por meio da riqueza de invenção e do inédito de soluções sintomáticas atípicas.

De modo geral, se o termo invenção se impõe para ajudarnos hoje é porque ele está profundamente ligado à ideia de que o Outro não existe, ele é profundamente ligado à ideia de que o grande Outro é uma invenção. Tanto ficamos com a ideia de que o grande Outro do simbólico existe, que o sujeito é simplesmente efeito do significante; e aquele que, de alguma forma, inventa, é o Outro. Não há Outro que se invente. Enquanto o Outro não existe, a ênfase muda do efeito para o uso, move-se para o saber-fazer do Outro. Isso não é somente o ponto de vista 'o sujeito é determinado pela linguagem, pelo Outro, é no Outro que isso acontece', é ao contrário a noção que o sujeito tem que saber-fazer, que ele tem que saber-fazer com o seu traumatismo. O Outro não existe significa que o sujeito está condicionado a tornar-se inventor. Ele é particularmente empurrado a instrumentalizar a linguagem (Miller, 2004a, p. 11).

Na psicose, o sujeito não tem como recurso a metáfora edipiana e as soluções típicas às quais ele se reportaria: ele se encontra, assim, condenado a fazer o trabalho do laço social contando com um radical - seu sintoma, do qual a eficácia trama sua singularidade com a comunidade, enodando, de maneira original, o simbólico do significante, o imaginário do corpo e o real do gozo. A referência à psicose acentua o caráter semblantizado da função da linguagem, sublinhando a estrutura do sujeito como objeção ao saber. O sujeito psicótico não espera o capitalismo ou a ciência para aparelhar o gozo à arte, à invenção e ao laço social, pois desempenhando a sua divisão com o apoio dos tesouros que ele tira da cidade: Suzon ou a arte da metamorfose. 


\section{O sujeito na cidade: coletividades e singularidades}

A vida em coletividade repousa sobre um certo número de leis e de regras que a tornam possível. Essas regras constituem um quadro que pode variar de um coletivo a outro, de um grupo a outro ou de uma cultura a outra, mas o que continua constante é que ele se dirige de modo indistinto a cada indivíduo compondo a comunidade. Essa indistinção funda seu próprio princípio e participa daquilo que é nomeado à permanência, à universalidade ou mesmo à transcendência da lei, da linguagem e da ordem simbólica.

Essa permanência é o que faz o enquadramento - nas instituições de cuidado ou de educação especializada - ser qualificada de "terapêutica” para os jovens cuja história é feita de rupturas de todas as sortes - afetivas e familiares, escolares e sociais. Dizemos que o quadro é seguro e estruturante. Contudo, esse quadro instituído é regularmente contestado, ultrapassado e questionado pelos jovens que nós acompanhamos. É sobre ele que nós conversamos quando estamos juntos; ele torna-se objeto de nossa atenção, alimenta as nossas conversas, nossas reflexões, nossos questionamentos, nossas dificuldades, nossas reuniões...

De modo contrastante, se o enquadre é comum, constatamos que ele é sempre mal estabelecido ou transgredido de uma maneira singular. Pelos desvios da clínica tentamos aproximarmo-nos da particularidade do "não" colocado pela singularidade daquele que faz objeção ao que está estabelecido. O enquadre é comum, no entanto, o "não" que cada sujeito apresenta-lhe em oposição é, por sua parte, singular, sem medida comum. Nós somos, então, convidados a entrar em outra dimensão, em outra lógica, que é a do coletivo e de seu enquadre, a lógica do um por um, do caso a caso, que faz sintoma dentro do próprio ideal da cidade. Essa manifestação singular se apresenta, então, como uma objeção ao enquadre coletivo, assim como o enquadre coletivo faz objeção à singularidade de cada caso - o sujeito como objeção ao instituído.

Então, como acolher e acompanhar as manifestações singulares, ditas fora do enquadre, fora de norma; e como conceder-lhes um lugar na cidade? Como tratar a tensão permanente entre o comum da cidade e a singularidade do sujeito? Como alternativa, considerando essas manifestações transgressivas singulares, ou fora do enquadre, como uma linguagem.

Para a psicanálise, o ser humano é definido inicialmente como um ser de linguagem - de saber e de cultura. A cultura constitui o lugar natural do ser falante. Sua textura simbólica determina o tecido. No entanto, essa relação simbólica não está reservada ao domínio do pensamento ou ao exercício da fala. Ela irriga toda a manifestação humana, as relações do sujeito com seus objetos, com os outros e com o seu próprio corpo... Do social à cidade. Isso concerne, logicamente, à concepção psicanalítica do sintoma - os sintomas do corpo e os sintomas sociais. No ensino de Freud e Lacan, entende-se o sintoma como fixação singular de gozo, próprio ao sujeito, impossível de universalizar-se (Soler, 
1998, p. 71). Ele representa uma satisfação substitutiva da libido, retorno do gozo recalcado. Para a psicanálise, o sintoma é uma linguagem, uma palavra silenciada a ser liberada, testemunhando o retorno de uma verdade reprimida, indexando-a ao ser real do sujeito. O trabalho analítico consiste em "fazer falar o sintoma" (Soler, 1998, p. 75) de maneira que ele se reduza à sua parte irredutível e necessária, para que o sujeito consiga deduzir um saber do sintoma e torne-se responsável.

Se o uso da palavra e a referência à linguagem caracterizam a natureza humana na ordem dos viventes, então, toda tentativa de redução da linguagem e de seus modos de expressão pode ser assimilada como uma violação fundamental à condição ou à essência de nossa humanidade: referimo-nos não somente aos direitos e às liberdades que flutuam em função dos contextos históricos, sociais e políticos, mas à natureza e à própria condição do ser. Assim, toda tentativa de supressão do sintoma, longe de competir com o bem-estar, com a educação ou a inserção social da criança, não contribui para reforçar suas dificuldades e comprometer suas possibilidades de acesso ao cuidado.

O analista, pelo contrário, institui-se como parceiro-sintoma do sujeito: forjado por Jacques-Alain Miller, esse sintagma designa o parceiro-gozo do sujeito (Miller, 1998), assim como corpo, ou outro, do qual o sujeito goza de um sintoma.

O que é um sintoma? Um meio de gozo; e, se eu estou aliado ao Outro, o Outro é, para mim, um sintoma, isto é, um meio de gozo de meu próprio corpo (Miller, 1998).

A continuidade do sintoma e do inconsciente - via interpretação do analista - ressoa não somente em termos de uma política psicanalítica do sintoma, mas testemunha o caráter político do inconsciente que interessa, em primeiro lugar, ao gozo próprio de cada-Um, aparelha-se e faz eco aos significantes e aos semblantes que atravessam a cidade (Lacan, 1967).

\section{Clínica, psicanálise, semblante e laço social}

A entrada em jogo do discurso analítico nas instituições e na cidade refletem uma dialética sensível entre psicanálise e laço social. A psicanálise interroga particularmente os laços entre o real - fundamento da clínica psicanalítica - e os semblantes necessários à instituição do laço social.

De fato, a clínica do primeiro Lacan se desenvolvia sobre o plano da palavra, do saber, da transferência e do parceiro-sintoma (Ponnou, 2016). Mas, em 1977, durante a abertura da Sessão Clínica ligada ao Departamento de Psicanálise da Université Paris 8, Lacan indexa o real como fundamento da clínica psicanalítica: não somente "isso nós dizemos de uma psicanálise” (Lacan, 1977), mais ainda, a clínica é “o real como impossível de suportar” (Lacan, 1977). A clínica psicanalítica reenvia o real que Lacan definiu como impossível de suportar. Referida ao real, a clínica escapa ao poder, do simbólico e do imaginário, e 
se declina segundo equívoco introduzido pelo uso do verbo "suportar": visto que ela não é suportada pelo significante - ela é, precisamente, isso que foge ao poder das palavras, das representações e dos saberes - ela se refere à dor humana. O insuportável. É uma clínica do inominável, possivelmente, uma clínica como nome disso que não tem nome. As referências ao discurso e à palavra encontram-se igualmente afetadas, uma vez que a passagem do simbólico ao real centra a clínica analítica, considerando os "fenômenos de ruptura da cadeia simbólica" (Miller, 1999) suscetíveis de produzir uma perda da enunciação, em outras palavras, de reintroduzir um sujeito no saber (Miller, 1982). Isso significa, para o analista, não se referir aos efeitos de estagnação da linguagem e do saber, mas construir uma clínica irônica (Miller, 1993), que "diz que o Outro não existe, que o laço social é, no fundo, uma trapaça, que não há discurso que não seja do semblante" (Miller, 1993, p. 7). Essa perspectiva chama-se "uma clínica universal do delírio" (Miller, 1993, p. 7), que acentua o caráter não segregativo da clínica analítica e apresentase como os modos mais ou menos típicos de gozo (Miller, 1983; Lacan, 1979, p. 218). A referência ao real institui a singularidade do sujeito como radical da clínica psicanalítica. O sintoma é como uma conjunção do simbólico e do real (Sla) ou, até mesmo, conjunção do saber e do gozo, e modalidade singular de nós da estrutura ou do laço social - sun-tithémi (do grego), sintoma - que é atribuído um lugar universal (Miller, 2004b).

A referência ao real desloca definitivamente, dos impasses categoriais, a clínica analítica. Ela aponta uma clínica além do édipo, uma clínica sem Outro, em que a estrutura do sujeito não revela categoria de relação íntima - carnal - do sujeito ao significante - "o real que emerge na linguagem" (Lacan, 2001, p. 476). A clínica do Outro que não existe tende a dissolver a pertinência dos usos categoriais por uma atenção renovada ao discurso do sujeito. A aposta consiste, então, em passar o indicador clínico da nosografia ao seguinte conceito ou à temática: clínica do sintoma ou do fantasma (Miller, 1983), clínica do discurso analítico, da análise, da entrada ou fim de análise (Miller, 1989; Miller, 1984), clínica da repetição, do super-eu, clínica do gozo (Miller, 1982), clínica dos nós (Miller, 2002) etc. Essas perspectivas permitem tanto o afastamento dos efeitos de estigma e de interferência da clínica clássica como da clínica do DSM - que são sempre do Outro: “[...] Ou nossa clínica será irônica, quer dizer, fundada sobre a inexistência do Outro como defesa contra o real - ou nossa clínica não será nada que não seja uma repetição da psiquiatria" (Miller, 1993, p. 8)...

Entretanto, essa referência ao real como fundamento da clínica analítica induz certas formas de paradoxos quanto à inscrição da psicanálise no debate contemporâneo dos saberes e do laço social. Segundo essa perspectiva, a psicanálise e a civilização e a psicanálise na civilização avançam em direções opostas. A primeira traz para o centro sua apreensão do real, enquanto a segunda institui-se como paradigma do simbólico. Consequência lógica: o lugar da psicanálise na cidade se torna inversamente proporcional ao seu progresso. Essa hipótese implica: quanto mais avançamos na história da psicanálise - sua clínica, seus 
conceitos, a formação dos psicanalistas - mais a inscrição da psicanálise na história e na trama do laço social se encontrará complexificada, provavelmente impedida.

Desde sua invenção por Freud, a psicanálise conheceu as tempestades e as épocas duradouras. A ideia de resistência, ou de dissidência, não é estrangeira ao movimento psicanalítico: ela parece hoje levada ao seu paroxismo, se não a um ponto de tensão raramente esperado. Essa situação é tão paradoxal que a psicanálise propõe soluções inéditas às novas declinações do mal-estar na civilização: depressão, autismo, hiperatividade, sofrimento no trabalho...

Sem dúvidas, o encolhimento do espaço analítico é contemporâneo das mudanças simbólicas em ação no tecido social: apoiadas no zênite do culto ao objeto e à desvalorização da palavra, declínio das ontologias e das figuras de autoridade pretendendo-se universal, angústia generalizada por um uso desenfreado da ciência (Miller, 2012; Miller, 2013)... Mas ainda procura-se no Outro as razões de um mal-estar estrutural ligado à trajetória assintomática da psicanálise na civilização. Denunciando a precariedade dos semblantes, a psicanálise interpreta o sintoma social no particular de cada um e conduz o sujeito à construção de um saber semidito no lugar da verdade - à elaboração de um saber do real. Ela revela a construção de um laço social que não se apoia mais em ilusão, mas na relação com a hiância, com a falha, com a descrença no Outro, no vazio irrecuperável, desvelando a responsabilidade e a criatividade do sujeito em sua relação com ele mesmo e com os outros.

Mas as possibilidades desse trabalho não são sem condições: que o analista possa constituir-se como um lugar onde nos endereçamos; que a psicanálise não seja banida dos serviços de cuidado e de educação pelos motivos administrativos, especulativos ou oportunistas; que o discurso analítico possa ainda ser difundido e marcar o sujeito em sua carne... Incumbidos de trazer, de modo vivante, o significante no real, somos também responsáveis pelas condições e possibilidades que implicam a fábrica de um semblante para a psicanálise, de semblantes suscetíveis de manterem vivo o lugar da psicanálise na cidade. Um semblante para um discurso que não seria sem semblante (Lacan, 2007)... Um chamariz, um gancho transferencial ao qual o analista poderia subscrever sem aceitar as razões: a cura, a verdade, o saber... Um semblante, um paradoxo sob a forma de questão - quais semblantes para a psicanálise? - suscetível de defender a política da psicanálise nos anos vindouros... E com ela, nosso saber-fazer e nossa criatividade.

Tradução de Isael de Jesus Sena e revisão gramatical de Aline Carvalho Cerqueira

Recebido em 12 de novembro de 2020 Aprovado em 24 de fevereiro de 2021 


\section{Referências}

BÉRAUD, Anne (Dir.). Agrafes et inventions dans la psychose ordinaire. Montréal: Le pont freudien, 2018.

BRUNO, Pierre. Lacan passeur de Marx. Toulouse: Érès, 2012.

FREUD, Sigmund. Études sur l'hystérie. Paris: PUF, 2002.

LA SAGNA, Phillippe. Les malentendus du trauma. La Cause Du Désir, Paris, n. 86, p. 40-50, 2014.

LACAN, Jacques. Écrits. Paris: Le Seuil, 1966a.

LACAN, Jacques. La logique du fantasme. Séminaire XIV, Unpublished, 1966b. Disponible sur: http://www.goagao.free.fr>. Consulté le: 10 janv. 2014.

LACAN, Jacques. Du discours psychanalytique. In: CONFERENCE AT UNIVERSITY OF MILAN, 1972, Milan. Conference... Milan, 1972. Disponible sur: <http://pagespersoorange.fr/espace.freud/topos/psycha/.../Italie.htm>. Consulté le: 10 janv. 2014.

LACAN, Jacques. Ouverture de la section clinique. Ornicar?, Paris, n. 9, 1977.

LACAN, Jacques. Lacan pour Vincennes!. Ornicar?, Paris, p. 17-18, 1979.

LACAN, Jacques. Autres écrits. Paris: Le Seuil, 2001.

LACAN, Jacques. D'un discours qui ne serait pas du semblante. Séminaire XVIII. Paris: Éd. du Seuil, 2007.

LACAN, Jacques. ...ou pire. Séminaire XIX. Paris: Le Seuil, 2011.

LAURENT, Éric. Psychanalyse avec les enfants. S.l.: S.e., 1991.

MILLER, Jacques-Alain et al. Scilicet. L'ordre symbolique au XXIe siècle. Il n'est plus ce qu'il était. Quelles conséquences pour la cure? Paris: Éd. École de la Cause freudienne, Rue Huysmans, 2012.

MILLER, Jacques-Alain et al. Scilicet. Un réel pour le XXIº siècle. In: CONGRÈS DE L'AMP, 9., 2013. Annales... Paris: Éd. École de la Cause freudienne, Rue Huysmans, 2013.

MILLER, Jacques-Alain. Du symptôme au fantasme et retour. Unpublished, Lecture given at the department of psychanalysis of the university Paris 8 . Paris, 1982a.

MILLER, Jacques-Alain. La clinique lacanienne. Unpublished, Lecture given at the department of psychanalysis of the university Paris 8. Paris, 1982b.

MILLER, Jacques-Alain. Du symptôme au fantasme et retour. Unpublished, Lecture given at the department of psychanalysis of the university Paris 8. Paris, 1983.

MILLER, Jacques-Alain. CST - Clinique Sous Transfert. Ornicar?, Paris, n. 29, 1984.

MILLER, Jacques-Alain. Le banquet des analystes. Inédit, Unpublished, Lecture given at the department of psychanalysis of the university Paris 8. Paris, 1989. MILLER, Jacques-Alain. Clinique ironique. La cause freudienne, Paris, n. 23, p. 7-13, 1993.

MILLER, Jacques-Alain. Le partenaire-symptôme. Unpublished, Lecture given at the department of psychanalysis of the university Paris 8. Paris, 1998.

MILLER, Jacques-Alain. La psychose ordinaire: La convention d'Antibes. Paris: Le Paon; Agalma-Le Seuil, 1999a.

Educação \& Realidade, Porto Alegre, v. 46, n. 1, e109165, 2021. 
MILLER, Jacques-Alain. Le réel de l'expérience analytique. Unpublished, Lecture given at the department of psychanalysis of the university Paris 8. Paris, 1999b.

MILLER, Jacques-Alain. Le désenchantement de la psychanalyse. Unpublished, Lecture given at the department of psychanalysis of the university Paris 8. Paris, 2002.

MILLER, Jacques-Alain. L'invention psychotique. Quarto, Paris, n. 80, 2004 a.

MILLER, Jacques-Alain. Pièces détachées. Unpublished, Lecture given at the department of psychanalysis of the university Paris 8. Paris, 2004b.

MILLER, Jacques-Alain. L'Autre méchant: six cas cliniques commentés. Paris: Navarin, 2010.

MILLER, Jacques-Alain. Progrès en psychanalyse assez lents. La Cause freudienne, Paris, v. 78, n. 2, p. 151-206, 2011. Disponible sur: <https://www.cairn. info/revue-la-cause-freudienne-2011-2-page-151.htm>. Consulté le: 10 janv. 2014.

NAVEAU, Pierre. Les psychoses et le lien social: Le noeud défait. Paris: Anthropos, 2004.

PONNOU, Sébastien. Le travail social à l'épreuve de la clinique psychanalytique. Paris: L'Harmattan, 2016.

SAURET, Marie-Jean. Malaise dans le capitalisme. Toulouse: Presses Universitaires du Mirail, 2009.

SAURET, Marie-Jean. L'effet révolutionnaire du symptôme. Toulouse: Érès, 2012.

SOLER, Colette. La politique du symptôme. Quarto, Paris, n. 65, p. 71-76, 1998.

STEVENS, Alexandre. Devant l'enfant violent, un cadre ou un bord. Excerpt of the intervention of 20.9.2018 at the Groupe CEREDA de La-Roche-sur-Yon. 2018. Disponible sur: <https://institut-enfant.fr/zappeur-jie5/devant-lenfantviolent-un-cadre-ou-un-bord/>. Consulté le: 18 janv. 2020.

Sébastien Ponnou, é psicanalista, professor na Université de Rouen Normandie, membro do Centre Interdisciplinaire de Recherche Normand en Education et Formation, CIRNEF, EA 7454. Suas pesquisas abordam os seguintes temas: clínica e teoria lacaniana, estudos psicanalíticos, problemáticas de saúde mental

ORCID: http://orcid.org/0000-0002-4778-9198

E-mail: sebastien.ponnou-delaffon@univ-rouen.fr

Editora-responsável: Fabiana de Amorim Marcello

Este é um artigo de acesso aberto distribuído sob os termos de uma Licença Creative Commons Atribuição 4.0 Internacional. Disponível em: <http:// creativecommons.org/licenses/by/4.0>. 